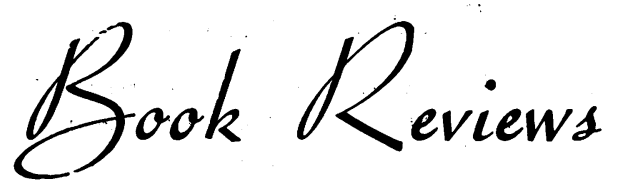

\section{BRITISH OBSTETRIC AND GYNAECOLOGICAL PRACTICE}

Edited by Sir Eardley Holland, M.D., F.R.C.P., F.R.C.S., F.R.C.O.G., and AlECK BOURNE, M.A., M.B., B.Ch., F.R.C.S., F.R.C.O.G. London: Wm. Heinemann, Ltd. I 955.

Gynaecology; Pp. xii $+84 \mathrm{I}$, with $37 \mathrm{I}$ illustrations, 8 in colour. $95 \mathrm{~s}$.

Obstetrics; Pp. xiv + I, I66, with 395 illustrations. II $5 \mathrm{~s}$.

These two books must be considered a major contribution to the literature. They reflect very well what they set out to do, namely to describe British practice in obstetrics and gynaecology, not that, as the Editors mention, this branch of British medicine is radically different from that of other countries but there are perhaps variations that stamp our work with an individuality of its own. The authors are widely chosen from all over the United Kingdom and although each contributor gives his opinion and views on his subject, it is to the credit of the Editors that no particular section is unbalanced or unrepresentative of current British opinion.

Before considering each book separately, it is worth while comparing them. Both are well set out and the level of photographs and X-rays is usually high. In each, one author takes a subject to discuss and thus while each chapter is authoritative this method does lead to lack of overall continuity, with repetition in some places and omission in others. It might well have been worth while omitting what one might call the ' routine' chapters at the beginning of each book-those on the 'Menstrual Cycle' and 'Physical Methods in Diagnosis' in the gynaecological book and those on the "Physiology of Reproduction' in the obstetric. 'They really add little that is new or cannot be read almost identically elsewhere, and their omission would save over a hundred pages in one case and $5^{\circ}$ pages or so in the other, and it must be admitted that both these books could do with some shortening. Both books also suffer by the author's name not being amalgamated with his respective chapter in the list of contents so that one has to look up each chapter to see by whom it was written.

Turning now to the larger book-that on obstetrics. It is perhaps invidious to pick out any particular chapters when the general level is so high, but four must be mentioned. Jeffcoate's ' Dystocia due to Abnormal Uterine Action' is probably the best account of this subject yet written and his classification is now widely recognized. Professor Keller's account of the 'Toxaemia of Pregnanc甲' is a model of clarity and concise exposition on thits difficult and ill-defined topic. The late Dr. Wallefs chapter on 'Breast Feeding' is a fitting memority to a man who devoted so much of his life to thils subject, and it is tragic to note also the death $\mathrm{ff}$ McIntosh Marshall who has summed up a lifes experience in his chapter on "Caesarian Section."w

In reading the other chapters one or two smo points were noted. In O' Sullivan's section on 'Inversion of the Uterus,' interesting for advocacy of the hydrostatic method of uterine placement, the blocks showing a woman having This done are printed upside down in one and of ifs side in the other. As the other two blocks ares the right way up this provides an interesting $\overrightarrow{\nabla b}$ baffling rotational effect. On the other hand ${ }^{t}$ Be picture of forceps being applied to the aftercomi head of a breech would be better for being turned on its side, as it is unusual to deliver a womar wherstoe is standing up, and it would emphasize the neeg for pulling the baby's body well back over the moth's abdomen so that its mouth is clear of the perineum. Is it also correct to say the 'forceps is applie and not the 'forceps are' or is this unnecessapy pedanticism on the author's part? It might afso be queried whether Lusbaugh's work justifigd amniotic embolism being known as his syndrome. Ian Jackson makes as much as can be out $\mathrm{f} f$ 'Dystocia due to Deformities of the Foetus, ${ }^{a}$ chapter much of which is covered in other sections and could well have been omitted. Dr. James' article on 'Psychiatry' in both books is good, beit again very repetitive and should have been fuse end $^{2}$ together to appear in one of the books only. The are mostly small points and do not detract fron $a$ book which must be considered in the forefront $\mathcal{Q} f$ modern textbooks.

Considering the gynaecological book, the subject is divided anatomically and this is satisfactory general, although the chapters on 'The Cervis' and 'The Corpus' are almost small books in the selves. Again in Jeffcoate's excellent and loffsp article on 'Abnormal Uterine Bleeding' we find a section on dysmennorrhoea inserted rather inaptify.

To my mind if one has to make comparisons this book is better than the one on obstetrics. Shorter, each chapter is of a high standard, with those of Read, Blakely and Stallworthy being outstandirfs. The short section by Charles Read on operatipe 
gynaecology should be read by all gynaecologists. Again, Chassar Moir sums up his extensive experience on vesicovaginal fistulas in a most valuable manner. Brew's chapter on 'The Vulva' has many excellent photographs and it is pleasing to note that the Editor's chapter on 'The Vagina' keeps well abreast of the other contributors.

These two books, despite their expense, should be bought by all interested in the subject. I am sure their success will justify future editions.

\section{DISEASES OF THE EAR, NOSE AND THRUAT IN CHILDREN}

By T. G. Wilson, M.B., B.Ch., F.R.C.S.I., M.R.I.A. Pp. xii +307 , with 145 illustrations. London: Wm. Heinemann, Ltd. I955. 70 s.

This book makes very pleasant reading. The author has unrivalled experiences in diseases of children and he gives very clearly his opinion and advice on the aetiology and management of many childish ailments. In addition he has quoted very fully from other textbooks and current articles of world literature and the result gives a useful review in one textbook. The author has also borrowed widely many figures and diagrams to augment those beautifully drawn by himself.

Parts of the book give very useful information. Full descriptions are made of the congenital abnormalities in various sites, of the differences between children and adults in anatomy and physiology of various structures such as the eustachian tube, middle ear and larynx. Deafness in children is described at length with the all important stress on the need for early auditory training, before the age of two if possible; lip-reading is, however, only accorded four lines of text. Defective speech is dealt with more fully than in most oto-laryngeal books and sinusitis, nasal allergy, laryngeal defects and neck conditions are well and fully considered.

It is always easy to be critical of other persons' work; everyone is entitled to his own opinion. Some statements appearing in this book, however, do not seem to accord with the general concensus of opinion. Only a few omissions in the text are noticeable, though not enough stress is given to some subjects and too much to some others.

The standard of illustration is high, although the choice of a few appears inappropriate. There seems room for additional diagrams to deal, with such subjects as the tracheostomy operation and the appearances on otoscopy and a need for cutting some, such as with the dissection and guillotining of tonsils.

While enjoying the book and paying tribute to the great interest it gives to the subject, some doubt is felt whether its value will justify the relatively high price charged and whether there is a demand for this type of book. It presupposes considerable knowledge of many aspects of the subject matter and yet goes fully into details on others.

Oto-laryngologists will already have specialized textbooks and articles, trainee specialists will need fuller textbooks anyway and paediatricians and general practitioners may regretfully find so much oto-laryngeal detail in some parts and not enough in others as to make them loathe to do more than skim through it in a library. This would be a pity as the contents are of great importance and much of it certainly needs to be more widely recognized.

I.G.R.

\section{PUBLIC RELATIONS IN MEDICAL PRACTICE}

By James E. Bryan. Pp. xiv +302 . London: Baillière, Tindall and Cox Ltd. 1955. 38s. 6d.

This book is a sincere attempt by a well-informed American layman to guide doctors in their professional relationships. The subjects discussed include the doctor's dealings with his colleagues and with the patient, as well as with the larger community. The burden of the book is a plea for humanity and a spirit of service. For the English reader, it is unfortunate that the best chapters are those which seek to apply these principles to such practical matters as hospital organization and payment of fees; the problems discussed here are mostly peculiar to the American health system.

\section{THE PHYSIOLOGICAL BASIS OF MEDICAL PRACTICE}

By C. H. Best, C.B.E., M.A., M.D., D.Sc., F.R.S. F.R.C.P., and N. BURKE-TAYLOR, V.D., M.D., F.R.S., F.R.C.S., F.R.C.P., M.R.C.S., L.R.C.P. Sixth edition. Pp. xiv $+1,358$, with 604 illustrations, 3 in colour. London: Baillière, Tindall \&zo Cox Ltd. 1955. 91s. 6d.

This edition includes much new material, although the total bulk has been slightly reduced. It will continue to be a popular textbook but nevertheless one could wish for certain improvements. Description of some of the clinical topics (such as the E.S.R.) is out of touch with present medical practice. Electrolyte balance is almost totally neglected and potassium is omitted completely from the list of toxic substances that accumulate in renal failure. References to clinical conditions should be restricted to those which illustrate physiological principles. Some descriptions of original work need to be more precise; thus in the account of Goldblatt's experiment it is important to state that he was working with dogs. The dates of quoted work should be given, especially where there is more than one paper by the same author. The page headings are sometimes anomalous; thus hypertension appears under the heading 'Venous blood flow.' The prose style is not easy to read; punctuation could be improved, some split infinitives re-united and jargon (such as 'osseous tissue' instead of ' bone ') avoided.

These shortcomings should not obscure one's respect for the book as a whole. It emphasizes the basic importance of physiology in clinical medicine and will be useful both to students and to practising clinicians. 